\title{
Research on Side Reform Strategies of Service Supply in Dazhou
}

\author{
Zibiao Cheng1, Chengduan Wang'2, Xiaoyi Liu ${ }^{3}$ \\ ${ }^{1}$ School of Finance and Economics Management, Sichuan University of Arts and Science, Dazhou, China \\ ${ }^{2}$ Party Committee Office, Sichuan University of Arts and Science, Dazhou, China \\ ${ }^{3}$ School of Finance and Economics Management, Sichuan University of Arts and Science, Dazhou, China \\ Email: 47872614@qq.com
}

How to cite this paper: Cheng, Z.B., Wang, C.D. and Liu, X.Y. (2018) Research on Side Reform Strategies of Service Supply in Dazhou. Open Journal of Social Sciences, 6, 243-250.

https://doi.org/10.4236/jss.2018.612021

Received: November 20, 2018

Accepted: December 26, 2018

Published: December 29, 2018

Copyright (C) 2018 by authors and Scientific Research Publishing Inc. This work is licensed under the Creative Commons Attribution International License (CC BY 4.0).

http://creativecommons.org/licenses/by/4.0/

\section{(c) (i) Open Access}

\begin{abstract}
Dazhou is a large industrial and agricultural city with a huge population. The proportion of service industry in GDP is lower than the secondary industry. Compared with the overall level of the whole country, there is a big gap, and the development potential of service industry is huge. There are three major obstacles to the supply-side reform of the service industry in Dazhou: unsuitable institutional supply and transformational development, uncoordinated consumption supply and market demand, and unbalanced talent supply and development needs. In order to solve these problems, it is required to strengthen the supply of the system, accumulate the power of transformation, improve the quality of supply, guide the return of consumption, strengthen the supply of talents, and create a dynamic state of Dazhou to promote the transformation and upgrading of the service industry. While maintaining the growth rate of the service industry, it must integrate with agriculture and industry, and provide services for the development of agriculture and industry and a platform to foster the new vitality of Dazhou's economic development.
\end{abstract}

\section{Keywords}

Supply Side Reform, Service Industry, Dazhou

\section{Introduction}

It is generally believed that the supply side reform originated from the Say's Law proposed in The Treaty of Political Economy by Say, the founder of Western supply economics [1]. On November 10, 2015, General Secretary Xi Jinping proposed the supply side reform for the first time in the 11th meeting of the Central Financial and Economic Leading Group. The domestic supply-side 
reform is mainly aimed at reforms in the areas of insufficient supply and unreasonable supply structure caused by administrative monopolies in some industries [2]. The long-term restriction of private capital entering the domestic service industry is a key industry that needs to undergo structural reforms on the supply side.

According to the plan of the Dazhou Municipal Government work report in 2017, Dazhou will make every effort to accelerate the development of service industry, and increase its proportion and level. The added value of the service industry in the city will be increased to more than $45 \%$ of the GDP. It will adjust three industrial restructures to 3:2:1, with an added value exceeding 80 billion yuan. The regional service industry center of the Sichuan-Chongqing-Shanxi Ministry will be basically established. The side reform of service industry supply is not only a new growth point for economic development of Dazhou, but also profoundly affects its economic restructuring and upgrading. It is necessary and urgent to thoroughly study the side reform of service industry supply.

\section{Significance of Promoting the Side Reform of Service Industry Supply}

In 2017, Dazhou's GDP reached 158.394 billion yuan, an increase of $8.2 \%$ on a year-on-year basis in terms of comparable prices. Among them, the added value of the primary industry was 32.213 billion yuan with an increase of $3.8 \%$; the added value of the secondary industry was 55.812 billion yuan with an increase of $8.1 \%$; and the added value of the tertiary industry (ie, the service industry) was 70.369 billion yuan with an increase of $10.5 \%$. The ratio of three industrial structures is 20.3:35.3:44.4 [3].

It can be seen from the above data that the service industry in Dazhou ranks first in the three industries. In 2016, the added value of service industry was 53.087 billion yuan, which exceeded 70 billion yuan in 2017, with a significant increase of nearly 17 billion yuan. However, the proportion of service industry in Dazhou's GDP is $44.5 \%$, which is still lower than Sichuan's service industry's share of the province's GDP of $49.3 \%, 7$ percentage points lower than the national average of 51.6\% [4]. In 2017, the proportion of added value of service industry in Beijing's GDP reached 80.6\% [5], that in Shanghai was 69\% [6], that in Guangdong Province was 52.8\% [7], and that in Zhejiang Province was 52.7\% [8]. Compared with these developed provinces, the development of service industry in Dazhou still has a lot of room to improve. It has certain practical significance to promote the side reform of service industry supply in Dazhou.

\section{Barriers to the Side Reform Strategy of Service Supply in Dazhou}

\subsection{Institutional Supply and Transformation Development Are Not Adapted}

China's economic development is not short of money, nor of people, but of in- 
stitutional supply. There are also problems of inadaptability between institutional supply and transformation development in Dazhou City in the process of transformation and development. For example, the trend of industrial transformation and integration is the general trend. The problem of supervision of emerging services is becoming increasingly prominent. It is particularly important to create a standardized and orderly legal business environment. However, the current supervision lacks standards and rigid constraints, and cannot meet the requirements of simplification and decentralization. The problems of administrative monopoly and market access in some service industries are prominent. Policy monopolies or semi-monopolies are still in modern service industries, such as telecommunications, postal, power supply, finance, insurance, civil aviation and railways. The market's fundamental role in resource allocation is difficult to fully exert, which restricts the development of modern service industry.

\subsection{Consumption Supply Is Not in Harmony with Market Demand}

First, the turnover rate of business education is high. At the end of 2017, Dazhou's permanent population was 5.6895 million, with a large and concentrated population, fewer shopping centers and strong consumption capacity. However, the shopping habits of citizens were to go to Chengdu and Chongqing to sweep goods or buy online, which due to the consumption loss was large. There is still a big gap between junior and senior high school education and key middle schools such as Chengdu, Chongqing and Mianyang. For example, in 2017, students of Chengdu No. 7 Middle School were admitted to key undergraduate universities as high as $98 \%$, the students in middle school of Sichuan Normal University was 82.75\%, and that of Dazhu Middle School, the best one in 2017, was only 60.6\%. The educational habit is to send children to study in Chengdu, Mianyang or Chongqing.

Second, the rate of medical loss is high. According to the statistical report issued by Chengdu Shell Research Institute, the residents of Dazhou who purchase the second-hand houses in Chengdu ranked the second in Sichuan account for $15.3 \%$ in the first half of 2018. Buying a house in other cities will also bring out the consumption of education, medical treatment, high-end clothing and so on. According to incomplete statistics, the annual outflow of Dazhou's consumer market is at least 2 billion yuan, and the outflow trend is very serious. During the 13th Five-Year Plan period, the vast majority of service industries did not have excess capacity, but faced with insufficient effective supply, especially in the education, medical, real estate and other high-end services market, which is difficult to meet the growing service demand of Dazhou residents. Therefore, service industry in Dazhou has a huge development space.

\subsection{Consumption Supply Is Not in Harmony with Market Demand}

First, talents in high-end service industry are shortage. Talents are the obstruc- 
tion that Dazhou needs to break through in its economic development. Located in the remote Daba Mountains, where there is a lack of regional attraction for high-end talents. The service industry in Dazhou has a great demand for high-quality talents such as high-level technical personnel and managerial personnel. However there is a general shortage of talents in high-end service industries such as product research and development, cultural creativity, technology outsourcing, financial innovation and so on, which is a huge obstacle to the further development of the service industry under the situation of lacking high-level, sophisticated and top-ranking talents.

Second, talent introduction mechanism is Unreasonable. Since 2012, Dazhou has implemented the policy of "thousands of great talents entering Dazhou" and recruited more than 1000 great talents, thus realizing the great accumulation of talents. However, due to the fact that this talent introduction mechanism is still in the process of exploring and running in with the old and new mechanisms, the design of the talent introduction mechanism also has the defect of "emphasizing quantity rather than quality, emphasizing academic qualifications rather than actual achievements". Almost all of the talents introduced are graduates of this year who have already made achievements in their work, while there are a few professionals with certain R \& D capabilities and middle and senior titles, and even have few strong R \& D teams, industry leaders and top talents. Therefore, these talents still cannot meet the demand of high-quality talents in high-end service industry, which restricts the innovation and high-end development of modern service industry.

\section{Side Reform Strategies of Service Supply in Dazhou}

\subsection{Strengthen Institutional Supply and Accumulate Transformational Motivation}

First, Formulating and promulgating the implementation opinions on the transformation and upgrading of the whole city. Emphasis should be laid on the sale of commercial housing, and measures such as housing accumulation fund, bank mortgage loan, financial subsidy for house purchase, monetization of housing reform and resettlement, and adjustment of personal purchase tax should be taken comprehensively. Supporting the de-inventory of real estate, carrying out a series of measures of "Double Hundred Projects" with steady growth of enterprises, and "One Enterprise One Policy" to help enterprises reduce the cost of electricity, gas, land and financing. Create a strong institutional guarantee for the development of service industry in Dazhou City.

Second, Increase support for emerging service industries. With the popularization of information technology and the Internet, emerging services have penetrated into all aspects of our lives, which have created an open, equal and standardized access system for these service market participants [2]. At the same time, efforts should be made to create a business environment ruled by law, break the monopoly mechanism of some industries, release the vitality of mi- 
cro-subjects, play the market allocate resources as a decisive role, break through the supply bottleneck with market power, and create a strong foundation for the development of emerging services in Dazhou.

Third, Strengthen the supply of relevant systems which led by scientific and technological innovation. Continuous support and improve enterprises' policies on research and development of new materials, technologies and products, implement more active policies on talent introduction, and formulate policies to encourage and support talent entrepreneurship. Therefore, it is suggested that Dazhou Municipal Committee and Municipal Government should strengthen the reform of the government itself, enhance the credibility and execution of the government, speed up the building of a government ruled by law and a service-oriented government, and transfer the service industry of Dazhou from a comparative advantage to a core competitive advantage.

\subsection{Improving Supply Quality and Guiding Consumption Reflux}

First, in terms of business and shopping, we should speed up the construction of Dazhou New Business Center, which integrates shopping, leisure, humanities and entertainment, and is full of leisure fun and rich shopping experience, such as Louvre Square, such as Red Star Meikailong, Lotus Lake Business Complex Project, Renhe Spring Business Complex Project, etc. to build a number of urban consumer business circles and improve the quality of service consumer goods. Through the implementation of the coordinated development of related industries, commodity consumption, tourism consumption, cultural consumption and other diversified integrated consumption environment, supply and demand matching can be realized, and Dazhou people's consumption can be left in Dazhou.

Second, in the field of education, Dazhou junior and senior high schools should try to retain local excellent primary and secondary students. Schools should strengthen the construction of their own teachers, improve the quality of teaching, strengthen the construction of style of study, to establish a good reputation for local citizens. Then, we should strive for the support of the competent educational authorities and appoint excellent teachers to study advanced educational concepts and methods in key middle schools such as Chengdu, Chongqing and Mianyang, so as to improve the level of teachers in Dazhou's education. Finally, we should strengthen the propaganda efforts to form an advantageous public opinion atmosphere in junior and senior high schools in our city, with the theme of good middle school environment, atmosphere, close to home, low fees, no school fees and scholarships for outstanding students.

Third, in housing, we should optimize the supply of real estate, improve the quality and efficiency of the building economy, and focus on promoting the construction of "billion-level" key projects such as Louvre New City Square, Red Star International Square, Renhe Commercial Square and Hongfan Baren Square [7]. To further enhance the quality and image of urban commerce, and to con- 
tinuously enhance the rationality, moderation and diversity of commercial real estate projects in spatial layout and construction time sequence. Moreover, efforts should be made in encouraging and guiding investment operators with investment strength and industrial resources, restricting low-level speculative development, and encouraging financial institutions to develop financial products for house purchase that meet the needs of different groups. At the same time, accelerate the revival of Tongchuan District, the construction of North of Xuanhan and Dazhu agglomeration areas, actively cultivate the "10 billion" agglomeration areas of Dachuan Yangliu to enhance the market radiation capacity.

\subsection{Strengthen Talent Supply and Build Vigorous Dazhou}

Strengthen school-enterprise cooperation and attach importance of professional training. Dazhou has been advocating the development of science and education, but the added value of the transformation of scientific research results is very low, and the dividends released for the service industry in the development of science and education city are small, because the supply of professional talents needed for the development of service industry is insufficient. Dazhou has five colleges and universities, such as Sichuan College of Arts and Sciences and Dazhou Vocational and Technical College. We should seize these educational resources, boldly encourage cooperation among colleges and universities, scientific research institutes, vocational schools and local enterprises, train a group of talents with both theoretical and practical expertise, and train a group of open and skilled talents who are familiar with national rules and adapt to market demand.

Furthermore, refer to the advanced mechanism of introducing talents, and speed up the training of innovative talents. Dazhou can refer to the three Implementing Measures for talent introduction formulated by Chengdu Municipal Bureau of Human Resources and Social Sciences in July 2017, to adhere the decisive role of the market in the allocation of human resources. Through the parts of the measures, combine with the market conditions of Dazhou City and the "thousands of great talents into Dazhou" plan, to cooperate the project of attracting capital, attracting technology, attracting talents and strengthening talent base. We should formulate supporting measures for introducing high-end and high-tech talents at home and abroad in the service industry. Meanwhile, accelerate the implementation of the training plan for innovative and entrepreneurial talents, vigorously introduce senior management and technical personnel in the service industry, and attract high-end talents in the service industry to gather in Dazhou. Then, expand international exchanges and cooperation by appointing a certain number of local personnel to train in developed countries and regions of service industry every year to form a diversified, open and fully competitive human resource allocation mechanism.

\section{Conclusions}

Dazhou should take the strengthening of institutional supply as the core, the 
promotion of consumption supply as the guide, and the supply of talents as the guarantee to promote the upgrading of service industry, and strive to build a service base with Dazhou characteristics, promote the overall, agglomeration and innovation development of service industry, to promote the decision-making and deployment of structural reform on the supply side of the service industry.

The research on supply-side structural reform of service industry needs a lot of data support. However, it is difficult to obtain relevant data such as consumption and education outgoing, and quantitative analysis is hard. Therefore, qualitative analysis is the main method. In the future, under the support of the Internet and big data, we should conduct accurate data analysis on the structural reform of the supply side of the service industry, and improve the research accuracy of the structural reform of the supply side of the service industry.

\section{Funding}

1) Sichuan Provincial Social Science Research High-level Research Team Sichuan Revolutionary Old Area Ecological Civilization Construction Research Team (Project No.: 18SCTD01).

2) Funded by Sichuan Tourism Development Research Center, Sichuan University Key Research Base of Philosophy and Social Sciences (LYC18-47).

3) Funded by Sichuan Revolutionary Old District Development Research Center 2017 Project Grant.

4) 2017 Sichuan Provincial Department of Education Research Project The Role of Farmer Professional Cooperatives in the Reform of Agricultural Supply Side-Taking Dazhou as an Example (17SA0144) 5. 2017 Dazhou Social Science Association Project Thinking on the Reform of Supply Side of Service Industry in Dazhou (DZ17C18).

5) Sichuan Provincial Social Science Research High-level Research Team Sichuan Revolutionary Old Area Ecological Civilization Construction Research Team (Project No.: 18SCTD01).

\section{Conflicts of Interest}

The authors declare no conflicts of interest regarding the publication of this paper.

\section{References}

[1] Zhang, C. (2016) Research on Destocking of Commercial Residential Buildings from the Perspective of Supply Side Reform-Taking the Western Region of China as an Example. Thesis, Guangxi University, Nanning, 6.

[2] National School of Economics, Department of Economics and Research (2016) China's Supply Side Structural Reform. People's Publishing House, Beijing.

[3] Sichuan Rural Information Network (2018) In 2017, the GDP of Dazhou Increased by $8.2 \%$ Year-on-Year.

http://www.scnjw.gov.cn/dz/article/5f91086a-025b-11e8-aa07-8f88de42bf91/?tdsour 
cetag=s_pcqq_aiomsg

[4] Dazhou Municipal People's Government (2017) Dazhou Yearbook. Sichuan Science and Technology Press, Dazhou, 57-60.

[5] In 2017, the Added Value of Beijing's Service Industry Reached 225.69.3 Billion Yuan, Which Was 2.7 Percentage Points Higher than That before the Pilot Project (2018). http://finance.qianlong.com/2018/0410/2510340.shtml

[6] Shanghai Statistical Bureau (2017) Shanghai Statistical Bulletin on National Economic and Social Development.

[7] Guangzhou Statistical Bureau (2017) Guangzhou Statistical Bulletin on National Economic and Social Development.

[8] Zhejiang Statistical Bureau (2017) Zhejiang Statistical Bulletin on National Economic and Social Development. 